\title{
Contraceptive self-injection knowledge, attitude and practices among female students of a tertiary health institution in south west Nigeria
}

\author{
Ajibola Idowu*, Emmanuel Osinusi, Loliya Esther Awubite, Ismat Olanrewaju Obisesan
}

Department of Community Medicine, College of Health Sciences, Iwo, Nigeria

Received: 07 December 2021

Accepted: 04 January 2022

\section{*Correspondence:}

Dr. Ajibola Idowu,

E-mail: idajibola@yahoo.com

Copyright: ( ) the author(s), publisher and licensee Medip Academy. This is an open-access article distributed under the terms of the Creative Commons Attribution Non-Commercial License, which permits unrestricted non-commercial use, distribution, and reproduction in any medium, provided the original work is properly cited.

\begin{abstract}
Background: Contraception is one of the key strategies to achieving sustainable developments but access has been low among youths in developing countries. It is thus imperative to contextually understand the uptake of one of the newly developed contraceptive methods among undergraduate Nigerian students. This study assessed knowledge, attitude and practices of students in Bowen University Teaching Hospital Ogbomoso on contraceptive self-injection (DMPA-SC). Methods: Descriptive cross-sectional design was employed among 167 consenting students who were recruited using stratified sampling method. Validated semi-structured, self-administered questionnaire was used for data collection. Both descriptive and inferential statistics were carried out.

Results: Mean age (SD) of the respondents was 21.9 \pm 2.2 . More than a quarter $(32.0 \%)$ of the respondents were not aware of contraceptive self-injection. Attitude to contraceptive self-injection was positive in $91 \%$ of those who were aware of it. However, just $2.4 \%$ of the contraceptive users ever used contraceptive self-injection. Cost considerations $(25 \%)$, fear of side effects (17\%), feeling of being not at risk of pregnancy (33.3\%) and lack of awareness (25\%) were the major barriers to uptakes of contraceptive self-injection among our respondents. Almost three-quarter (71.0\%) of the respondents had good knowledge of self-injection contraception. Age, (AOR=5.038, 95\% CI=1.846-1.274) and attitude $(\mathrm{AOR}=3.286,96 \% \mathrm{CI}=2.253-4.794)$ were the determinants of good knowledge on contraceptive self-injection. Conclusions: In spite of the predominant positive attitude and good knowledge on contraceptive self-injection, uptake was low in the study population. Authors recommend increased awareness campaign regarding this method of contraception among health-related students who can be vanguards of information dissemination on the product.
\end{abstract}

Keywords: Attitude, Contraception, Knowledge, Self-injection, Youths

\section{INTRODUCTION}

Contraception is a method of preventing pregnancy by altering the normal process of ovulation, fertilization, and implantation. ${ }^{1}$ Globally, the number of women demanding contraceptive services has increased tremendously from barely 900 million in 2000 to almost 1.1 billion in $2020 .^{2}$ Yet, according to the World Health Organization (WHO), an estimated 1.1 billion women of reproductive age group (15-49 years) have a need for family planning worldwide in 2019. Out of these, 842 million are using contraceptive methods, and 270 million have an unmet need for contraception. ${ }^{2}$ It is estimated that not less than 214 million of women in the developing world wish to avoid pregnancy but are not using any form of modern contraception. ${ }^{3}$

World Bank data revealed that unmet need for contraception ranged from $11 \%$ (in Middle East and North Africa) to $26 \%$ (Sub-Saharan Africa) while met need ranged from 25 percent (in Sub-Saharan Africa) to 63 percent (Latin America and the Caribbean). In Nigeria, the 2018 Demographic and Health Surveillance (DHS) report revealed that the contraceptive prevalence rate (CPR) for modern contraception was $17 \%$ and the twoyear contraceptive discontinuation rate was as high as $41 \%$. Unmet contraceptive need was $19 \%$ for married women and $48 \%$ for unmarried women. Also, 
contraceptive demand among married women was $36 \%$ and only $34 \%$ of contraceptive demands was met. ${ }^{5}$

Yet, contraception helps to protect the sexual and reproductive rights of persons and helps them to decide free of coercion and discrimination if and when to have children. ${ }^{6}$ It prevents unwanted pregnancies and unsafe abortions which can lead to maternal deaths especially in countries where medical abortion is not legal. WHO reported that use of modern contraceptives prevented at least 308 million unintended pregnancies in 2017 alone and that meeting the needs of people for modern contraceptive methods would avert an additional 67 million unintended pregnancies, yearly. ${ }^{7}$ Contraception also offers a range on non-health benefits including helping women to benefit from educational opportunities. It also helps to achieve responsible and sustainable population growths. ${ }^{2}$

Presently, there are varieties of modern contraceptive techniques including barrier methods such as male and female condoms, cervical caps, sponge and spermicides. Others include intra uterine contraceptive devices (IUCDs), surgical methods and hormonal contraceptives. These methods all have varied effectiveness. In developing countries, one of the most preferred contraceptive options is the hormonal method. ${ }^{8}$ Analysis of demographic and health survey (DHS) of 48 African countries by Tsui et al, revealed that injectable hormonal contraceptive is the most utilized method in Sub-Saharan Africa. ${ }^{9}$ Hormonal contraceptive works in different ways including prevention of ovulation, thickening of cervical mucus so that sperm cannot enter the uterus or by making the lining of the uterus thinner to prevent implantation. ${ }^{10}$ Hormonal contraceptives come in different forms including the birth control pill, the vaginal ring, the contraceptive skin patch, implants, hormone-releasing contraceptive coils and injectables (often called shots).

Injectables are reversible long-acting contraceptive (LARC) methods, shown to be about 20 times more effective than the oral contraceptive pills when used correctly. ${ }^{11}$ They consist of progesterone-only and the combined (oestrogen and progesterone) preparations. Depot medroxy progesteron acetate (DMPA), also called Depo-Provera is an example of progestin only contraceptive method which is given intramuscularly every three months. The other type of progesten only contraceptive is the norethisterone enanthate (NET-EN), which is less popular. However, DMPA is known to be an effective contraceptive method as only 0.3 pregnancies per 100 women occur within one year of correct use. ${ }^{12}$ In order to overcome access barriers to contraception, the depot medoxy progesterone acetate sub-cute (DMPA-SC) has been developed. ${ }^{13}$ It is given once every 3 months like DMPA-IM but at a much lower dose of $104 \mathrm{mg} / 0.65 \mathrm{ml}$ administered into fatty areas of the body. Sayana Press which is a brand of DMPA-SC, was developed by Pfizer pharmaceutical company. It combines the drug and needle in a single prefilled Uniject system, designed only for a single use. The single-unit design makes DMPA-SC easy to use as health workers do not have to be doing the measuring of the drug before use. ${ }^{14}$ Thus, these unique features of Sayana Press make it very suitable for community-distributions and for self-administration at home by women. This arrangement makes contraception available to women without the need to transport themselves to the hospital and thereby lessening the stigma which is often associated with contraceptive demands in developing countries. Hence, WHO recommends that selfadministered injectable contraception (DMPA-IM or DMPA-SC) should be made available as an additional approach to deliver injectable contraception for individuals of reproductive age. ${ }^{7}$ DMPA-SC is currently approved for use in a number of sub-Saharan African countries and has been a lunched for use in Nigeria. ${ }^{15}$ Empirical evidences found significantly higher rates of contraceptive continuation with self-administration of DMPA as compared with administration by a health worker. $^{16,17}$

Introduction of DMPA-SC has the potential to improve contraceptive access particularly in the Covid-19 pandemic era in which there is frequent interruption in the supply chains of medical commodities including contraceptives. The ensuing widespread lockdowns to prevent viral spread in several countries increases the risk of unprotected sex and restricted access to contraception. ${ }^{18}$ Thus, DMPA-SC has the potential to help improve contraceptive access in line with the goals of the United Nations Family Planning 2020 (FP2020) which is to reach the unreachable with modern contraceptive services. ${ }^{19}$ It can also help to achieve the sustainable development goal (SDG)- 3.7 of ensuring universal access to sexual and reproductive health services including family planning. ${ }^{20}$

Since a lunch of Sayana Press in Nigeria in 2014, empirical evidences show high feasibility and acceptance of this contraceptive method among women in the country. ${ }^{21,22}$ However, there has been dearths of information regarding DMPA-SC especially among Nigerian university students who are mostly adolescents and youths with high risks of unprotected sexual activities. Thus, the current study had the objective of assessing the knowledge, attitude and practice of health sciences students on DMPA-SC. Data generated form this study can be beneficial to policy makers in designing more robust interventions to improve contraceptive access the Nigerian youths.

\section{METHODS}

\section{Description of study area/study population}

The study was conducted among students of Bowen University Teaching Hospital, Ogbomoso, Nigeria which is the clinical arm of the College of Health Sciences, Bowen University, Iwo. The hospital is one of the privately owned missionary teaching hospitals in Nigeria managed using Christian ideologies. The hospital has tripartite functions of medical research, health manpower trainings 
and offering specialist cares in all areas of medicine. Founded as Baptist Medical Center, Ogbomoso by the Nigerian Baptist Convention in 1908, the hospital metamorphosed to a teaching hospital (BUTH) in 2009. Currently, the hospital has over 400 bed capacity. It also has about 450 students pursuing various degrees in Medicine and Surgery, B.Sc. Nursing, B.Sc. Physiotherapy and B.Sc. Medical laboratory Sciences. Asides these courses, BUTH also runs a diploma in Nursing Sciences programme. All consenting students who had stayed in BUTH for at least 3 months prior to the survey were recruited into the study. Most students studying Diploma in Nursing sciences were on outside posting during data collection and were thus excluded from the study.

\section{Sample size calculation}

Lesly Kish formula for estimating sample size in a population of less than 10,000 inhabitants was used to estimate the minimum sample size. We assumed that $10 \%$ of our respondents would be aware of contraceptive selfinjection based on report from similar Nigerian study. ${ }^{23}$ Assumption of $10 \%$ non-response rate was made and corrected for, while the margin of error was placed at $5 \%$. Thus, a minimum sample size of 153 was estimated but 167 respondents participated in the study.

\section{Sampling techniques}

Stratified sampling method was used to recruit eligible respondents. Available clinical courses in BUTH were stratified and subjects recruited using proportionate sampling method. Respondents from each stratum was estimated by dividing the number of students in the stratum by the total number of students in BUTH campus then multiplying the result by our estimated sample size. Study participants were then recruited from each stratum using simple random method (Balloting).

\section{Data collection instrument/methods}

Data were collected between July and August, 2021 using semi-structured, self-administered questionnaire developed via reviewing extant literature. The questionnaire collected information on biodata of the respondents, their knowledge, attitude and practice regarding contraceptive-self injection. Questionnaire administration was done by a group of five medical students who were adequately trained on questionnaire administration to youths.

\section{Data management}

Each questionnaire received from respondents was field edited daily to ensure completeness of the required information. Data were then entered in to Statistical Package for Social Science (IBM for Windows) version 22 for analysis. Categorical data were summarized using percentages and displayed in tables and charts. Continuous variables were summarized using mean and standard deviation. At the bivariate level, Chi-squared test was used to compare categorical variables. A stepwise binary logistic regression model was built at the multivariate analysis level. Variables imputed into the model were selected based on whether they were statistically significant at the bivariate level. Odds ratio (OR) and confidence intervals were obtained to identify the predictors of knowledge of contraceptive self-injection among the respondents.

Attitude of respondents to contraceptive self-injection was assessed by positively phrasing 10 questions. Responses were placed on a Likert's scale ranging from 5 (strongly agreed) to 1 (strongly disagreed). Maximum score obtainable was 50. Respondents who had scores of at least 30 points were classified as having positive attitude. Those who scored less than 30-points were classified has having negative attitude to contraceptive self-injection.

Similarly, respondents' knowledge on contraceptive selfinjection was assessed by positively phrasing eight questions with responses ranging from yes (2-points), to no (1-point) and don't know (0-point). A score of 10 and above qualified a respondent as having good knowledge while respondents with lesser points were adjudged to have had poor knowledge of contraceptive self-injection.

\section{Pretesting}

Our questionnaire was pretested among 30 medical and nursing students of the Ladoke Akintola University of Technology, Ogbomoso, an institution which was different from the one used for the main study. They were selected using convenience sampling method. The exercise assisted us to know whether our questions were good enough to elicit required responses. Ambiguous questions were rephrased or entirely removed in line with our study objectives. Besides, face construct was used to assess the internal consistency of questions in the questionnaire.

\section{Ethical consideration}

Ethical Review Committee of Bowen University Teaching Hospital, Ogbomoso gave ethical approval to conduct the study. Written informed consents were obtained from each study participants after the study objectives were clearly explained to them. Participation in the study was entirely voluntary and students were allowed to opt out at any stage they are no longer comfortable answering our questions. Confidentiality was assured by making the questionnaire anonymous and by ensuring that only the principal investigator had access to the computer used in storing the data from the study.

\section{RESULTS}

Of the 180 questionnaires administered, 167 were returned satisfactorily completed ( $93 \%$ response rate). Mean age of the respondents was $21.9 \pm 2.2$. Majority $(72.4 \%)$ of the 
respondents were $20-24$ years of age and $41.9 \%$ of them were studying medicine and surgery. While $97.6 \%$ of them were Christians, $1.8 \%$ respondents were married and $85.5 \%$ were Yorubas by tribe (Table 1 ).

Table 1: Socio-demographic characteristics of respondents.

\begin{tabular}{|lll|}
\hline Variable & Frequency N=167 & Percent \\
\hline Age (years) & \multicolumn{2}{l|}{} \\
\hline$<20$ & 23 & 13.8 \\
\hline $20-24$ & 121 & 72.4 \\
\hline $25-29$ & 23 & 13.8 \\
\hline Mean \pm SD & $21.9 \pm 2.2$ & \\
\hline Course of study & & \\
\hline MBBS & 70 & 41.9 \\
\hline Physiotherapy & 66 & 39.5 \\
\hline $\begin{array}{l}\text { Medical laboratory } \\
\text { science }\end{array}$ & 31 & 18.6 \\
\hline Religion & & \\
\hline Christianity & 163 & 97.6 \\
\hline Islam & 3 & 1.8 \\
\hline Traditional & 1 & 0.6 \\
\hline Marital status & & \\
\hline Single & 164 & 98.2 \\
\hline Married & 3 & 1.8 \\
\hline Tribe & & 85.6 \\
\hline Yoruba & 143 & 3.0 \\
\hline Igbo & 5 & 1.8 \\
\hline Hausa & 3 & 9.6 \\
\hline Others & 16 & \\
\hline
\end{tabular}

More than a quarter $(32.0 \%)$ of the respondents were not aware of contraceptive self-injection. Of those who were aware, social media was the most predominant source of information; reported by $22.8 \%$ of the respondents (Figures 1 and 2).

Regarding knowledge on contraceptive self-injection, $20.3 \%$ of the respondent did not think it is a simple procedure. More than a quarter $(28.0 \%)$ of the respondents did not know that self-injection contraception can be done by any woman who is trained to do it while $27.1 \%$ of them did not think the procedure is safe for young women. More than half $(53.4 \%)$ of the respondents did not think that contraceptive self-injection can be used for emergency contraception while $13.6 \%$ of them did know that Contraceptive self-injection can improve contraceptive access (Table 2).

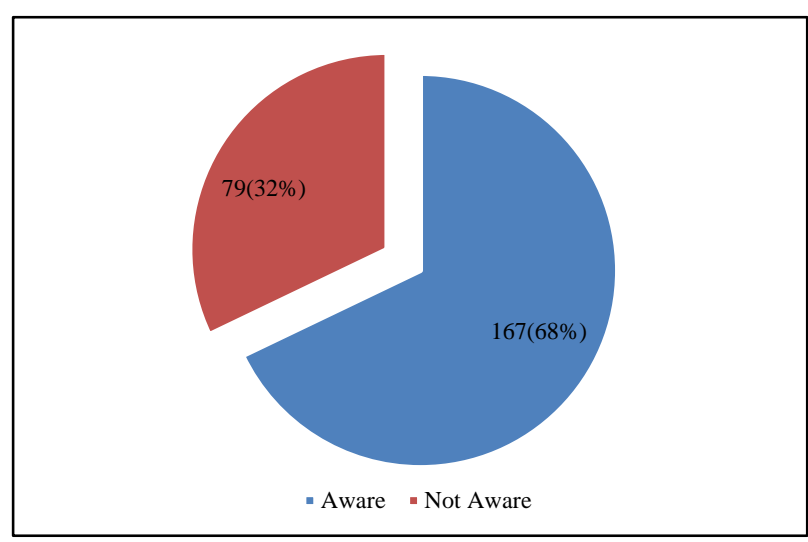

Figure 1: Respondents' awareness level on selfinjection contraception among respondents.

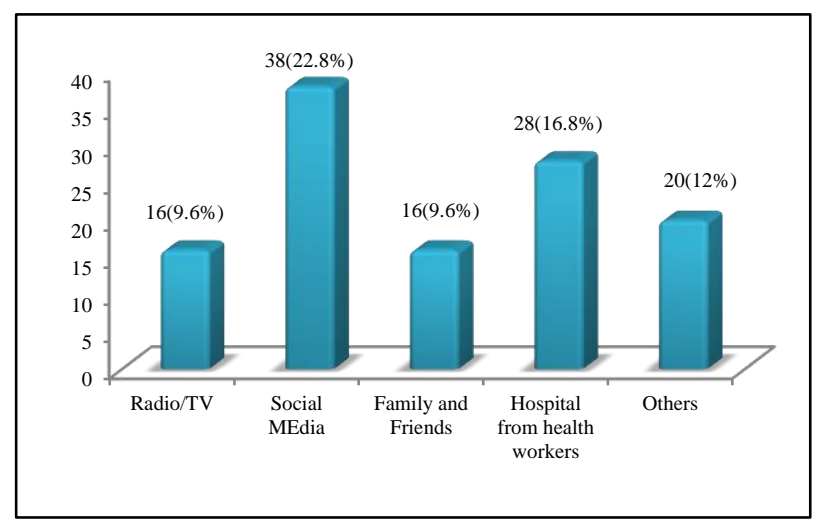

Figure 2: Sources of information about self-injection contraceptive.

Table 2: Knowledge of self-injection contraception among respondents.

\begin{tabular}{|c|c|c|}
\hline Statement & $\begin{array}{l}\text { True } \\
\mathbf{N}(\%)\end{array}$ & $\begin{array}{l}\text { False } \\
\mathbf{N}(\%)\end{array}$ \\
\hline Self-injection contraception is a simple procedure & $94(79.7)$ & $24(20.3)$ \\
\hline Self-injection contraception can result in infection if carried out in unhygienic environment & $111(94.1)$ & $7(5.9)$ \\
\hline Self-injection contraception can be employed by any woman & $85(72.0)$ & $33(28.0)$ \\
\hline Self-injection contraception is safe for young women & $86(72.9)$ & $32(27.1)$ \\
\hline Self-injection contraception can be used as an emergency contraception & $55(46.6)$ & $63(53.4)$ \\
\hline Self-injection contraception is administered once every three months & $80(67.8)$ & $38(32.2)$ \\
\hline $\begin{array}{l}\text { Self-injection contraception reduces the stress of having to go to the hospital for contraceptive } \\
\text { services }\end{array}$ & $103(87.3)$ & $15(12.7)$ \\
\hline Self-injection contraception makes contraception easily accessible to women & $102(86.4)$ & $16(13.6)$ \\
\hline
\end{tabular}


Table 3 shows that only $7.2 \%$ of the respondents had ever used any form of contraception while just $2.4 \%$ of the contraceptive users ever used contraceptive self-injection. Nurses and friends were the main people who trained the respondents on contraceptive self-injection procedure. Raised blood pressure and irregular menses were experienced by $66.7 \%$ of the self-injection contraceptive users. Also, $66.7 \%$ of the self-injection contraceptive users started the procedure when they were 20-24 years of age.
All self-injection contraceptive users got the injection at the hospital and were willing to recommend the procedure to their friends. Cost considerations $(25 \%)$, fear of side effects $(17 \%)$, feeling of not being at risk of pregnancy $(33.3 \%)$ and lack of awareness $(25 \%)$ were the major barriers to uptakes of contraceptive self-Injection among our respondents. However, attitude of those who were aware about contraceptive self-injection was positive in $91 \%$ of cases (Figure 3 ).

Table 3: Respondents' level of utilization of self-injection contraception.

\begin{tabular}{|c|c|c|}
\hline Variables & Frequency & Percentage \\
\hline \multicolumn{3}{|l|}{ Ever used contraception } \\
\hline Yes & 12 & 7.2 \\
\hline No & 155 & 92.8 \\
\hline \multicolumn{3}{|c|}{ Ever used self-injection contraception } \\
\hline Yes & 4 & 2.4 \\
\hline No & 163 & 97.6 \\
\hline \multicolumn{3}{|c|}{ Age at first use of self-injection contraception } \\
\hline$<20$ & 0 & 0.0 \\
\hline $20-24$ & 3 & 66.7 \\
\hline $25-29$ & 1 & 33.3 \\
\hline \multicolumn{3}{|l|}{ Trained by } \\
\hline Midwife & 0 & 0.0 \\
\hline Friend & 2 & 50.0 \\
\hline Others & 0 & 0.0 \\
\hline \multicolumn{3}{|c|}{ Ever experienced side effects } \\
\hline Yes & 3 & 75.0 \\
\hline No & 1 & 25.0 \\
\hline Types of side effects & $\mathbf{n}=\mathbf{3}$ & Multiple response \\
\hline Weight gain & 1 & 33.3 \\
\hline Raised blood pressure & 2 & 66.7 \\
\hline Irregular menses & 2 & 66.7 \\
\hline Breast pains & 1 & 33.3 \\
\hline Other (please specify) & 0 & 0.0 \\
\hline \multicolumn{3}{|c|}{ Willing to recommend self-injection contraception to others } \\
\hline Yes & 4 & 100.0 \\
\hline No & 0 & 0.0 \\
\hline \multicolumn{3}{|c|}{ Place where self-injection contraception was obtained } \\
\hline Hospital & 4 & 100.0 \\
\hline Chemist shop & 0 & 0.0 \\
\hline Pharmacy & 0 & 0.0 \\
\hline Others & 0 & 0.0 \\
\hline \multicolumn{3}{|l|}{ Payment mode } \\
\hline Self & 2 & 50.0 \\
\hline Spouse & 0 & 0.0 \\
\hline Parent & 0 & 0.0 \\
\hline Friend & 2 & 50.0 \\
\hline \multicolumn{3}{|l|}{ Reasons for non-use $\mathrm{N}=12$} \\
\hline Lack of awareness & 3 & 25.0 \\
\hline Fear of side effects & 2 & 17.0 \\
\hline Not at risk of pregnancy & 4 & 33.3 \\
\hline Cost consideration & 3 & 25.0 \\
\hline
\end{tabular}


Table 4: Determinants of respondents' knowledge on self-injection contraception.

\begin{tabular}{|c|c|c|c|c|c|c|}
\hline \multirow[b]{2}{*}{ Variables } & \multicolumn{2}{|c|}{ Knowledge of self-injection } & \multirow[b]{2}{*}{$\chi^{2}$} & \multirow[b]{2}{*}{$P$ value } & \multirow[b]{2}{*}{ AOR } & \multirow[b]{2}{*}{$95 \% \mathrm{CI}$} \\
\hline & $\begin{array}{l}\text { Good N=118 } \\
n=71.0 \%\end{array}$ & $\begin{array}{l}\text { Poor } N=49 \\
29.0 \%\end{array}$ & & & & \\
\hline Age (years) & & & 0.456 & $0.012 *$ & 5.038 & $1.846-6.274$ \\
\hline$<20$ & $15(65.2)$ & $8(34.8)$ & & & & \\
\hline 20-24 & $86(71.1)$ & $35(28.9)$ & & & & \\
\hline 25-29 & $17(73.9)$ & $6(26.1)$ & & & & \\
\hline Course of study & & & 4.595 & 0.100 & 0.809 & $0.549-1.192$ \\
\hline MBBS & $52(74.3)$ & $18(25.7)$ & & & & \\
\hline Nursing Sciences & $0(0.0)$ & $0(0.0)$ & & & & \\
\hline Physiotherapy & $49(74.2)$ & $17(25.8)$ & & & & \\
\hline Medical Laboratory Science & $17(54.8)$ & $14(45.2)$ & & & & \\
\hline Tribe & & & 3.089 & 0.378 & 0.781 & $0.541-1.126$ \\
\hline Yoruba & $102(71.3)$ & $41(28.7)$ & & & & \\
\hline Igbo & $4(80.0)$ & $1(20.0)$ & & & & \\
\hline Hausa & $3(100.0)$ & $0(0.0)$ & & & & \\
\hline Others & $9(56.3)$ & $7(43.8)$ & & & & \\
\hline Knowledge on contraception & & & 2.531 & 0.061 & 3.482 & $0.124-4.379$ \\
\hline Poor & $29(61.7)$ & $18(38.3)$ & & & & \\
\hline Good & $89(74.2)$ & $31(25.8)$ & & & & \\
\hline \multicolumn{3}{|c|}{ Attitude to self-injection contraception } & 20.400 & $0.001 *$ & 3.286 & $2.253-4.794$ \\
\hline Negative & $3(20.0)$ & $12(80.0)$ & & & & \\
\hline Positive & $115(75.7)$ & $37(24.3)$ & & & & \\
\hline
\end{tabular}

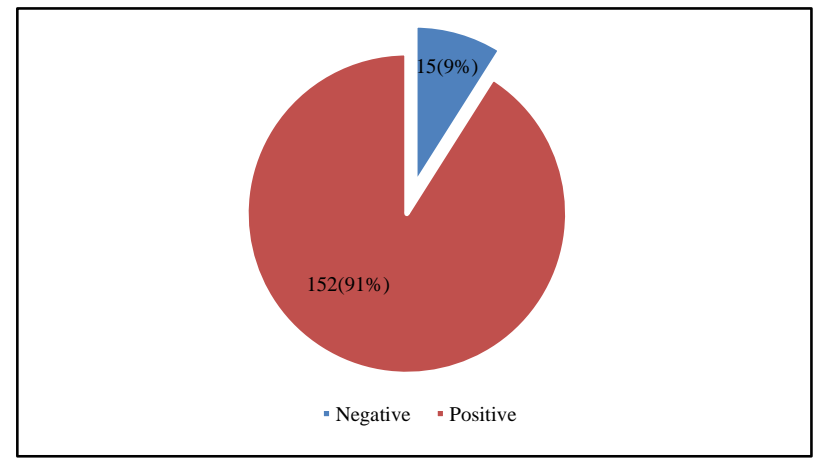

Figure 3: Respondents' attitude to contraceptive selfinjection.

Table 4 reveals that less than three-quarter $(71.0 \%)$ of the respondents had good knowledge of self-injection contraception. Respondents who were 25-29 years of age were five times more likely to possess good knowledge of self-injection contraception when compared to students in other age categories $(\mathrm{AOR}=5.038,95 \% \mathrm{CI}=1.846-6.274)$. Similarly, respondents with positive attitude were significantly more likely to have good knowledge of selfinjection contraception compared to those with negative attitude $(\mathrm{AOR}=3.286,96 \% \mathrm{CI}=2.253-4.794)$.

\section{DISCUSSION}

Majority $(68.0 \%)$ of the respondents in the current study were aware of contraceptive self-injection. However, awareness level among our respondents was higher than what was reported by Eremutha and Gabriel in which only $37.7 \%$ of Nigerian women were aware of this method of contraception. ${ }^{23}$ Reason for the higher awareness level in the current study could have been due to the attributes of study participants used. Our respondents were undergraduate students studying health-related subjects. They are expected to have been exposed to good quality contraception-related information in general and on contraceptive self-injection specifically. Exposure to contraceptive information could have been through didactic class lectures and informally through sociamedia which was stated as source of information in $22.8 \%$ of the respondents. Our findings are in agreements with results from a study conducted among undergraduate students in Kano, Nigeria by Datti et al, in which internet was the main source of contraceptive knowledge in $87.7 \%$ of the interviewed students. ${ }^{24}$ Thus, authors recommend that the wide acceptability and usage of the different social media platforms be leveraged upon for correct information dissemination to improve contraceptive knowledge among Nigerian undergraduates.

Attitude of the respondents in the current study to contraceptive self-injection was largely favourable. This is in agreement with findings from past contraceptive studies among young people. Hogmark et al concluded that majority of medical students in India had positive attitude to contraception and contraceptive counselling. ${ }^{25} \mathrm{~A}$ multicenter study among nursing students by Sanz-Martos et al 
revealed contraceptive attitudinal score to be 43.45 on a scale of $0-50 .{ }^{26} \mathrm{~A}$ study by Cover et al among adolescents in Uganda revealed that contraceptive self-injection was generally favourable to the respondents. ${ }^{27}$ Reproductive health policy makers can take advantage of this favourable attitude to make contraceptive self-injection more readily available to undergraduate Nigerian students.

In the current study, less than three-quarter of the respondents had good knowledge of contraceptive selfinjection while $20.3 \%$ of them did not consider it to be a simple procedure. Past studies have demonstrated that many students in health-related disciplines have poor contraceptive knowledge. For instance, Ukoha and Mooi in a study among Nigerian nursing students revealed that $47.7 \%$ of their respondents possessed inadequate knowledge of Implanon. ${ }^{28}$ In another study by van Zyl et al, among Health Sciences students in Tanzania, half of the respondents were not aware of subdermal implants and $34.8 \%$ have not heard of intrauterine devices. ${ }^{29}$ In Nigeria, Aigbiremolen et al, revealed that only $31.2 \%$ of undergraduate students had good knowledge of contraceptive methods and their benefits. ${ }^{30}$ However, Zainab et al reported that $87.7 \%$ of undergraduate Nigerian students had good contraceptive knowledge but the study did not assess respondents' knowledge on contraceptive self-injection. ${ }^{31}$ In spite of the fact that contraceptive selfinjection has been widely recommended by the WHO and the fact that the technology has proven to be highly costeffective in improving contraceptive access, knowledge of young women about this relatively new contraceptive method is still relatively poor. ${ }^{32}$ Authors thus advocate for a mass campaign about contraceptive self-injection among Nigerian students. The campaign should incorporate training of undergraduate health sciences students on the procedure involved to self-inject so that they can be vanguards of this contraceptive method to their friends studying non-health related courses.

The current study revealed that only $7.2 \%$ of the respondents had ever used any form of contraception while just $2.4 \%$ of the contraceptive users ever used contraceptive self-injection. This finding is similar to reports from the study by $\mathrm{Zyl}$ et al, in which only $10.5 \%$ undergraduate contraceptive acceptors were using injectables. ${ }^{29}$ However, the contraceptive prevalence rate in the current study was much lower when compared with findings from past Nigerian studies. For example, Aigbiremolen et al revealed current contraceptive utilization rate among Nigerian undergraduate students to be $37.7 \% .^{30}$ Utoo et al also showed a much higher contraceptive usage rate $(85.5 \%)$ among undergraduate students in North Central Nigeria. ${ }^{33}$ The rate reported in these studies were however not specific to contraceptive self-injection. Meanwhile, the observed low contraceptive prevalence rate in the current study could have been due to the low sexual activities amongst students in the study setting as reported in a past study. ${ }^{34}$ Being a Christian private tertiary health institution, students in our study setting are subjected to stringent rules and regulations which does not provide enabling environment for establishments of sexual relationships compared to students in public schools who have more freedom. Also, students in the institution used for the current study are encouraged to practice sexual abstinence in line with the doctrines of the Christian faith.

Majority of the self-injection contraceptive users started the procedure when they were 20-24 years of age. This could have been due to the relatively low awareness level regarding this contraceptive method and the fear of side effects such as high blood pressure and irregular menses which were reported by $66.7 \%$ of the users. All selfinjection contraceptive users in the current study got the injection at the hospital and were willing to recommend the procedure to their friends. This could indicate that the commodity is not readily accessible to youths. Efforts should be made by sexual and reproductive health policy makers, to make contraceptive self-injection readily available, accessible and affordable to the Nigerian youths. These efforts will help to reduce the currently high burden of unwanted pregnancies and unsafe abortions among young Nigerian girls.

Almost three-quarter $(71.0 \%)$ of the respondents had good knowledge of self-injection contraception. Many studies had revealed high knowledge rate of undergraduate students on contraceptives. ${ }^{35}$ The fact that our respondents were clinical students could have been responsible for the good knowledge among majority of them. Meanwhile, respondents who were 25-29 years of age were five times more likely to possess good knowledge of self-injection contraception when compared to students in other age categories. This could have been due to the fact that older students could have had more years of exposure to reproductive health information when compared to younger ones who are just being introduced to clinical tutorship. Similarly, respondents with positive attitude were significantly more likely to have good knowledge of self-injection contraception compared to those with negative attitude. Both attitude and knowledge are often interrelated and good determinants of health of practice.

Thus, authors recommend introduction of simple easy to understand contraceptive modules in the university curricular in Nigeria. This will improve the knowledgebase of most Nigerian students on the subject of contraception, increase contraceptive uptakes, reduce the rate of unplanned pregnancies and reduce maternal mortality rates from unsafe abortions.

This study has some limitations. This study may not be totally free from self-reporting bias as respondents may have given answers which are not true reflective of their sexual and contraceptive practices for the fear of victimization from the university authority. However, the fact that questionnaire was made anonymous and the research goals clearly explained to them would have minimized this bias. 


\section{CONCLUSION}

Practice of contraceptive self-injection was low among the students in the study setting. This is in spite of the generally favourable attitude and good contraceptive knowledge. There is need for a well-articulated awareness campaign on the benefits of contraceptive-self injection. Efforts should be made to make this contraceptive commodity readily available to young Nigerian girls to reduce the rate of unsafe abortion amongst them.

\section{ACKNOWLEDGMENTS}

We hereby acknowledge the students in College of Health sciences of Bowen University, Nigeria who took time to complete our questionnaires.

Funding: No funding sources

Conflict of interest: None declared

Ethical approval: The study was approved by the Institutional Ethics Committee Bowen University Teaching Hospital, Ogbomoso

\section{REFERENCES}

1. Encyclopaedia of Children's Health. Contraceptionmeaning, Definition, Purpose, Description, Risks. Available

from: http://www.healthofchildren.com/C/Contraception.ht ml. Accessed on 7 December 2021.

2. World Health Organization. Family planning/contraception methods. Available from: https://www.who.int/news-room/fact-

sheets/detail/family-planning-contraception.

Accessed on 5 December 2021.

3. WHO. Contraception. Available from: https://www.who.int/health-

topics/contraception\#tab=tab_1. Accessed on 5 December 2021.

4. 4. The World Bank. Public Health at a GlanceUnmet Need for Contraception. Available from: http://web.worldbank.org/archive/website01213/WE B/0_CO-17.HTM. Accessed on 5 December 2021.

5. National Population Commission, Abuja, Nigeria and ICF Rockville MU. The Federal Republic of Nigeria Nigeria Demographic and Health Survey 2018 National Population Commission Abuja, Nigeria. 2019.

6. Starrs AM, Ezeh AC, Barker G, Basu A, Bertrand JT, Blum R, et al. Accelerate progress- sexual and reproductive health and rights for all: report of the Guttmacher-Lancet Commission. Lancet. 2018;391(10140):2642-92.

7. WHO. Self-administration of injectable contraception. Available from: https://www.who.int/publications/i/item/WHO-SRH20.9. Accessed on 5 December 2021.

8. Darroch JE. Trends in contraceptive use. Contraception. 2013;87:259-63.
9. Tsui AO, Brown W, Li Q. Contraceptive practice in sub-Saharan Africa. Popul Dev Rev. 2017;43(1):16691.

10. Rivera R, Yacobson I, Grimes D. The mechanism of action of hormonal contraceptives and intrauterine contraceptive devices. Am J Obstet Gynecol. 1999;181(5):1263-9.

11. Marrie Stope. Injectable contraceptive | Marie Stopes Timor-Leste. Available from: https://www.mariestopes.tl/what-we-do/injectable/. Accessed on 5 December 2021.

12. Medscape. What is the efficacy injectable DMPA for contraception? Available from: https://www.medscape.com/answers/258507109038/what-is-the-efficacy-injectable-dmpa-forcontraception. Accessed on 6 December 2021.

13. World Health Organization. Answering questions and dispelling common myths about a new type of injectable contraception Subcutaneous DMPA key facts: $2019 . \quad$ Available from: https://www.rhsupplies.org/fileadmin/uploads/rhsc/T ools/DMPA_Kit/Files/Handouts_for_decision_make rs/DMPA-SC_advocacy_handouts_ 4_facts_2019.pdf. Accessed on 6 December 2021.

14. Khan ME, Bhatnagar I. Challenges in introducing new contraceptive methods: a case study of India. Int Quart Community Health Educ. 2015;35(4):387-401.

15. Nigeria Tribune Online. Without self-care, universal health coverage will elude Nigerians- FG. Tribune Online. Available from: https://tribuneonlineng.com/without-self-careuniversal-health-coverage-will-elude-nigerians-fg/. Accessed on 5 December 2021.

16. Burke HM, Chen M, Buluzi M, Fuchs R, Wevill S, Venkatasubramanian L, et al. Effect of selfadministration versus provider-administered injection of subcutaneous depot medroxyprogesterone acetate on continuation rates in Malawi: a randomised controlled trial. Lancet Glob Health. 2018;6(5):e56878.

17. Cover J, Namagembe A, Tumusiime J, Nsangi D, Lim J, Nakiganda-Busiku D. Continuation of injectable contraception when self-injected vs. administered by a facility-based health worker: a nonrandomized, prospective cohort study in Uganda. Contraception. 2018;98(5):383-8.

18. Aly J, Haeger KO, Christy AY, Johnson AM. Contraception access during the COVID-19 pandemic. Contracept Reprod Med. 2020;5(1):17.

19. FP2020. Strategy 2016-2020. Family Planning 2020. Available from: http://www.familyplanning 2020.org/strategy. Accessed on 8 February 2020.

20. Sustainable Development Goals. SDG Indicators. Available from: https://unstats.un.org/sdgs/ report/2019/. Accessed on 27 January 2020.

21. Enyindah CE, Mmom FC. Contraception with depot medroxy progesterone acetate (DMPA) in Port Harcourt, South-South Nigeria. J Med Biomed Res. 2015;14(2):5-12. 
22. Liu J, Shen J, Schatzkin E, Adedeji O, Kongnyuy E, Onuoha C, et al. Accessing DMPA-SC through the public and private sectors in Nigeria: users' characteristics and their experiences. Gates Open Res. 2018;2:73.

23. Eremutha F, Gabriel V. Awareness, knowledge, and perception about Sayana press $^{\circledR}$ contraceptive technology in Nigeria. Trop J Obstet Gynaecol. 2019;36(3):459-64

24. Ahmed ZD, Sule IB, Abolaji ML, Mohammed Y, Nguku P. Knowledge and utilization of contraceptive devices among unmarried undergraduate students of a tertiary institution in Kano State, Nigeria. Pan Afr Med J. 2017;26:103.

25. Hogmark S, Klingberg-Allvin M, GemzellDanielsson K, Ohlsson H, Essén B. Medical students' knowledge, attitudes and perceptions towards contraceptive use and counselling: A cross-sectional survey in Maharashtra, India. BMJ Open. 2013;3(12):e003739.

26. Sanz-Martos S, López-Medina IM, Álvarez-García C, Clavijo-Chamorro MZ, Ramos-Morcillo AJ, LópezRodríguez MM, et al. Young nursing student's knowledge and attitudes about contraceptive methods. Int J Environ Res Public Health. 2020;17(16):1-13.

27. Cover J, Lim J, Namagembe A, Tumusiime J, Drake JK, Cox CM. Acceptability of contraceptive selfinjection with DMPA-SC among adolescents in Gulu District, Uganda. Int Perspect Sex Reprod Health. 2017;43(4):153-62.

28. Ukoha WC, Mooi NM. Nursing students' knowledge, attitude and use regarding an implanted contraceptive method. Afr J Nurs Midwife. 2019;21(2):1-16.

29. van Zyl P, Brisley C, Halberg L, Matthysen M, Toerien M, Joubert G. The use, knowledge and attitudes regarding hormonal contraceptive products of female first-year students in a Faculty of Health Sciences. South Afr Fam Pract. 2019;61(5):190-6.

30. Aigbiremolen AO, Chukuma BD AC. Contraception among tertiary students: knowledge, use and behaviour. Glob J Med Res. 2014;14(2):1-7.

31. Ahmed ZD, Sule IB, Abolaji ML, Mohammed Y, Nguku P. Knowledge and utilization of contraceptive devices among unmarried undergraduate students of a tertiary institution in Kano State, Nigeria 2016. Pan Afr Med J. 2017;26.

32. WHO. WHO consolidated guideline on self-care interventions for health: sexual and reproductive health and rights. Geneva: World Health Organization; 2019.

33. Utoo BT, Mutihir TJ, Utoo PM. Knowledge, attitude and practice of family planning methods among women attending antenatal clinic in Jos, North-central Nigeria. Niger J Med. 2010;19(2):214-8.

34. Idowu A, Olowookere SA, Israel OK, Akinwumi AF. Human papillomavirus vaccine acceptability and uptake among medical and paramedical students of a Nigerian tertiary health institution. Am J Public Health Res. 2019;7(4):143-50.

35. Coetzee MH, Ngunyulu RN. Assessing the use of contraceptives by female undergraduate students in a selected higher educational institution in Gauteng. Curationis. 2015;38(2):1535.

Cite this article as: Idowu A, Osinusi E, Awubite LE, Obisesan IO. Contraceptive self-injection knowledge, attitude and practices among female students of a tertiary health institution in south west Nigeria. Int J Reprod Contracept Obstet Gynecol 2022;11:323-31. 